\title{
Open Source Web Platform for the Analysis of Academic Spin-offs
}

\author{
Fernando Almeida ${ }^{1)^{*}}$, Eugénio Cunha ${ }^{2)}$ \\ ${ }^{1)}$ Polythecnic Institute of Gaya, Univesity of Porto and INESC TEC \\ Av. dos Descobrimentos 333, V.N.Gaia, Portugal \\ 1)almd@fe.up.pt \\ ${ }^{2)}$ Polythecnic Institute of Porto and INESC TEC \\ Rua Dr. Roberto Frias s/n, Porto, Portugal \\ ${ }^{2)}$ eugenio.s.cunha@gmail.com
}

\begin{tabular}{|c|c|}
\hline Article history: & Abstract \\
\hline $\begin{array}{l}\text { Received } 18 \text { June } 2018 \\
\text { Revised } 23 \text { August } 2018 \\
\text { Accepted } 23 \text { August } 2018 \\
\text { Available online } 28 \text { October } 2018\end{array}$ & $\begin{array}{l}\text { Universities have assumed an increasingly important role in transferring } \\
\text { technology to society with a strong economic impact. The companies originated } \\
\text { from the academic environment, called academic spin-offs, have fostered the }\end{array}$ \\
\hline $\begin{array}{l}\text { Keywords: } \\
\text { Academic spin-offs } \\
\text { Entrepreneurship } \\
\text { Open source } \\
\text { Software engineering } \\
\text { Technology transfer activities } \\
\text { Web development }\end{array}$ & $\begin{array}{l}\text { by young students and researchers who seek to launch their own business and } \\
\text { generate new jobs in society. However, the number of existing studies on academic } \\
\text { spin-offs is limited and restricted to the specific national realities, and the results of } \\
\text { these studies are typically incorporated only in scientific manuscripts. In this sense, } \\
\text { this study proposes a web platform that allows the analysis of academic spin-offs } \\
\text { according to multiple dimensions, such as firm, institutions, individual, localization, } \\
\text { science parks, financial data and corporate actions. The application is built } \\
\text { exclusively in open source technologies and allows data to be explored in real-time } \\
\text { and interactively. The results obtained allow us to evaluate the behavior of the } \\
\text { application regarding fundamental elements in the success of the adoption of a Web } \\
\text { application, such as usability, security, interoperability and portability. }\end{array}$ \\
\hline
\end{tabular}

\section{INTRODUCTION}

A fundamental mission of the universities has been the creation of new knowledge through scientific research, in which the performance of these educational institutions was measured only through the quality of teaching and academic publications. However, over time, the role of universities has changed, taking a more increasing important role in the society with the appearance of "entrepreneurial university" concept [1]. According to this concept, universities must also play an active role in the direct commercialization of the research outcomes with new and different mechanisms of knowledge transfer to external entities. One of these mechanisms consists in the creation of academic spin-offs, to which knowledge is transferred and which are responsible for commercialization and the creation of economic and social value.

Reference [2] defines an academic spin-off as "a brand new company which formed by who were a part of an organization that concerning about a university or research institution intellectual research". Reference [3] adopts a slightly different definition "academic spin-off is a company that has either a university or at least one academic (full, associate, or assistant professor; or Ph.D. candidate, research fellow, or technician) among the founders, regardless of the presence of a formal commitment from the parent university". Although there isn't a universally accepted definition, they all involve the transfer of knowledge and technologies from the university to the academic spin-off [4]. In accordance with this situation, it is verified that most founders of university spin-offs are scientists or

\footnotetext{
${ }^{*}$ Corresponding author
} 
engineers with some business skills. Most of the projects also involve multi-founder teams, being common to find the involvement of several researchers, students or teachers from diverse educational institutions [5].

Literature has referred to the importance of stimulating the transfer of knowledge through the creation of academic spin-offs, especially in high technology areas destined to markets with high growth potential [6] [7]. Universities are looking for new ways to create competitive advantage and generate value. Academic spin-offs appear also as a key to regional development, which is a primary of the universities' mission [8]. In several European countries, as in the USA, there has been a substantial increase in the number of established academic spinoffs [9] [10] [11]. Reference [12] emphasizes three reasons for this growth: (i) companies created from the activities carried out at universities are better prepared to recognize their skills and establish relationships with strategic partners; (ii) the academic spin-offs process is less sensitive to changes in the global economic climate when compared to licensing agreements with established firms, tending to work as a counter-cyclical; and (iii) the viability of spin-off companies tends to be superior when compared to start-ups.

Despite the importance of academic spin-offs in the economy and society, studies on this process are still relatively scarce and need to be better understood in their multiple dimensions. The lack of standardization and centralization of information about the companies that result from academic spin-offs has given rise to the idea of creating a platform that gathers the various data about them, for public access and for academic studies. In this sense, two main contributions are given by this paper: (i) proposal of an academic repository of spin-offs that is built using exclusively open source technologies; and (ii) assessment of the impact offered by this solution considering multiple dimensions and looking to its relevance to the scientific community at European and international level. The manuscript is organized as follows: Firstly, the study contextualizes the most significant related works developed on academic spin-offs, considering both conceptual frameworks and web platforms. Then, the methods used to building the application are described. Subsequently, the main results of the projects are presented. Finally, the conclusions are drawn.

\section{RELATED WORKS}

Literature fundamentally has two types of studies that approach the process of analyzing of academic spin-offs. In the first group, it is possible to find studies that propose a conceptual framework for analyzing the performance and impact of academic spin-offs. In the second group, appear Web platforms that allow the analysis of national spinoffs created by universities and research centers in a given country or region.

\section{A. Conceptual Frameworks}

The oldest conceptual framework integrating multiple dimensions is composed of four pillars [13]: (i) resources; (ii) capabilities; (iii) mission; and (iv) impeding elements. This conceptualization considers simultaneously indigenous aspects and the contextual factors. In total the conceptualization consists of four dimensions, thirteen elements, and sixty-five variables.

Reference [14] proposes a conceptual framework to understand the several antecedents of academic entrepreneurship (e.g., individual, organizational and institutional factors) and the main consequences of spin-offs including scientific, educational and commercial outputs. Individual level factors including demographic characteristics, career trajectories and psychological features seem to be associated with engaging in academic entrepreneurship. Organizational factors are mid-level variables as characteristics of the university/department including peer influence, climate and leadership. In institutional factors two macro-level variables are included: the affiliation to a scientific discipline and the effect of specific national regulations and public policies. Both factors inform academic engagement as they shape the norms and rules relevant for researchers, either because they are official government regulations or because they are the more implicit structural rules of conduct. This conceptualization considers that consequences of academic entrepreneurship engagement can be measured in terms of scientific outcomes, educational outputs and commercial outputs.

Reference [15] presents a conceptual framework composed of eight dimensions: (i) role of university; (ii) technology transfer process; (iii) regional context; (iv) founder's background; (v) performance analysis; (vi) impact dimensions; (vii) public policies; and (viii) support organizations. This conceptualization also adds a total of 38 elements divided by each dimension. This study also emphasizes that the main explored dimensions on university spin-offs include the process of technology transfer, the role of the university in the society, the regional context of the university and the impact of university spin-offs in national economies. 


\section{B. Web platforms}

\section{1) TASTE Project ${ }^{\dagger}$}

TASTE project was initiated in 2000 by the University of Bologna, in Italy, when they started by collecting information about spin-off Italian universities. The aim of the study includes: (i) to systematically map entrepreneurship from Italian university labs; (ii) to provide reliable data on how science-based entrepreneurship unfolds and generate wealth; and (iii) to better understand the determinants of high-growth entrepreneurship. The project is based on three pillars: (i) individuals, (ii) organizations (spin-offs); and (iii) academic institutions. With the initial research, the project originated the TASTE database, which includes longitudinal time information on the population of 55.000 academic researchers, employed by 2.400 departments of 95 Italian universities between 2000 and 2017. The database has around 200 tables and 3000 variables and it is structured in five domains: (i) institutional; (ii) contextual; (iii) firm; (iv) individual; and (v) knowledge.

The results of the TASTE project have implication for both management theory and public policy. It contributes to understanding how scientists are engaged in knowledge-transfer activities, show how the evolution of entrepreneurship team diversity influences the performance of spin-off firms and understand how the exposure to different institutional logics affects scientists' engagement in knowledge-transfer activities.

2) Spin-outs $U K^{\prime}$

Spin-outs UK project gives a list of university spin-offs in the United Kingdom (UK), with information on its origins, activities, growth and current status, providing a series of continuous and regularly updated data. This project is developed by Young Company Finance. It initially focused on Scotland, but later was extended to the whole UK. The project offers an online platform that is freely available to the community. A full list of spin-offs and universities can be accessed without any payment. However, in order to obtain information about the market sector, company status, and financial information about each spin-off, a paid subscription is required to download the database.

The database contains more than 2000 university spin-offs and 150 universities. This project has led to a number of pertinent conclusions on how this environment has evolved, in particular the highlight of regions and sectors with higher spin-off growth rates.

3) $F O R N Y^{\S}$

FORNY is a joint program between the Research Council of Norway and Innovation Norway. It was established as a program in 2000, but has existed as a project since 1995.FORNY is designed to increase wealth creation in Norway by commercializing research-based business ideas with considerable market potential. The program finances the stimulation of ideas in R\&D groups and the evaluation and realization of such ideas at commercialization units. FORNY is designed to encourage students, researchers and research administrators focus more attention on the potential commercialization of research results from R\&D units.

FORNY program aimed to contribute to: (i) the change of attitudes and behavior in the research institutions to commercialization; (ii) to establish professional organizations and systems for the commercialization of research at the research institutions; (iii) to make competent and relevant commercialization assistance available; (iv) researchbased industry development across the country and (v) increased cooperation and learning among research institutions, entrepreneurs, investors, industry, and the government authorities.

\section{METHODS}

The study incorporated the development of a web platform for the analysis of academic spin-offs. For this purpose it was necessary to carry out a requirements survey process, the choice of technologies for the development of backend and frontend, process modeling, and the definition of an architecture that allows the communication and integration between the various modules.

\section{A. Requirements}

Requirements can be seen as objectives and functionalities desired and specified by the client. They are critical to capturing the features offered by a software engineering project. Reference [16] states that they give a description of the various functions those users need or want to be implemented.

The web platform is divided into two main components: (i) backend and (ii) frontend. The backend allows the administrator to manage the platform data. For this purpose, the following requirements are implemented:

https://eventi.unibo.it/taste

http://www.spinoutsuk.co.uk

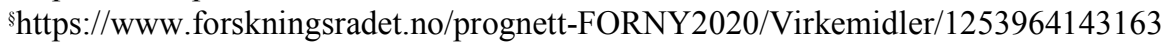


1. Authentication - allows the administrator to $\log$ in to the application. The password is encrypted in the database;

2. Import data - the administrator can import data about the spin-offs and founders. This information is stored in Comma Separated Values (CSV) or Excel files (XLS/XLSX);

3. Manage data - the administrator can directly in the backend add a new university spin-off or update data on a spin-off. For instance, the administrator can change the state of a spin-off (e.g., active to dissolved). In case a spin-off is dissolved it becomes important to register the dissolved date.

The frontend is public access. These requirements were established based on previous identified similar initiatives, and looking to the studies published by the research community in the field of entrepreneurship and academic spin-offs. The frontend allows the user to perform the following operations:

1. Explore spin-offs list-allows the user to view the spin-offs registered in the application. Each spin-off has information on the parent organization, faculty/R\&D center, incorporation date, district and status. This information is depicted in Fig. 1. It is also possible to get more information for each spin-off, such as address, web page, email, founders, and corporate actions (e.g., financials, such as merger, take-over, consolidation; strategy, such as internationalization, name change, partnerships; or recognition, such as general news in press, awards, certification;

2. Explore results - allows the user to explore the number of university spin-offs created by geographical area, per year, by university, by R\&D institutions, and by activity sector. Additionally, it becomes possible to consult the number of employees per year and the operating revenues generated by university spin-offs per year.

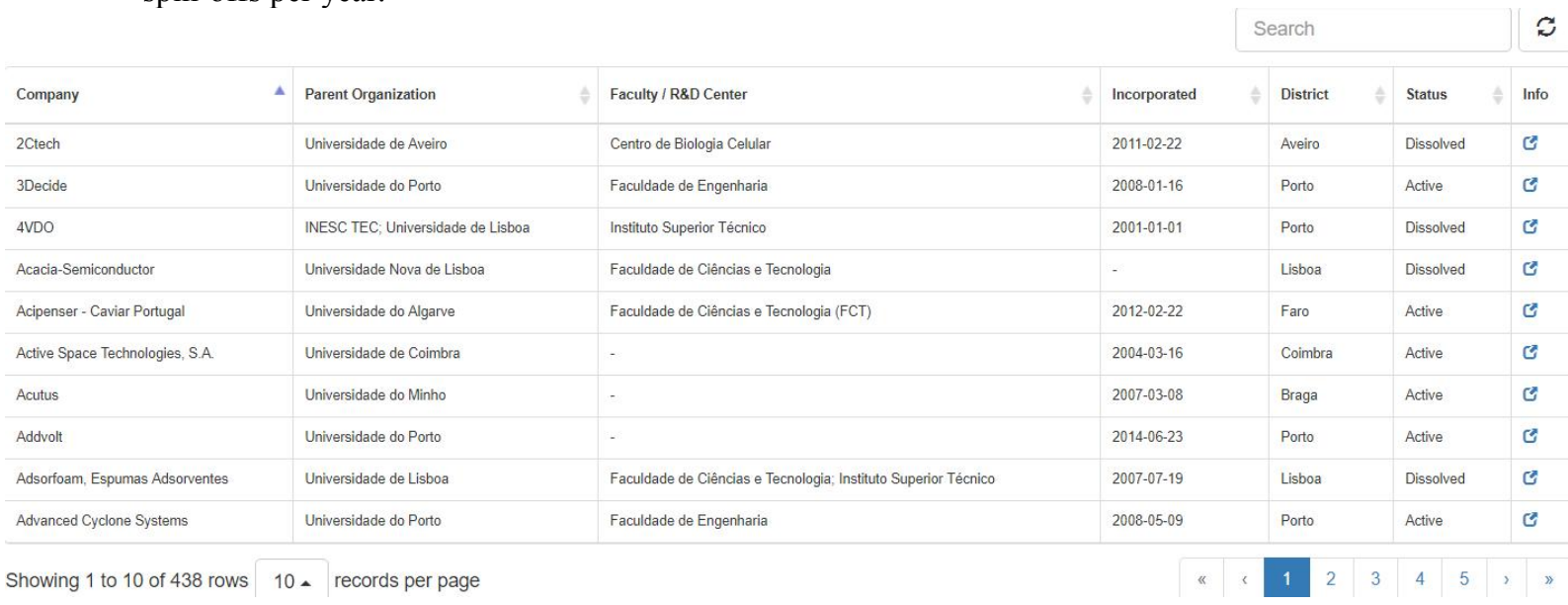

Fig. 1 Visualization of university spin-offs

\section{B. Technologies, Frameworks and Libraries}

A significant number of technologies were adopted in the development of this project. A common point in all of them is the exclusive use of open source technologies. References [17] [18] advocate that open source solutions bring important benefits in terms of cost, community support, security and interoperability. Additionally, open source software is well suited for education and research [19]. The source code can be inspected and modified, and derivative software can be written and distributed using the same or a compatible open source license without any copyright issues. These characteristics turn open source software very useful for research purposes.

In the development of the application, considering transversely all its modules, the following technologies were used:

i. HTML5: markup language used for the creation of dynamic web pages that are interpreted by browsers;

ii. CSS: cascading style sheets that allow formatting and layout of an HTML document. This language facilitates the maintenance of a consistent layout throughout all the web pages of the application;

iii. JavaScript: client-side language that through the use of scripts facilitates interaction with the user and dynamically changes the contents of an HTML document. This technology was particularly useful in the process of rendering and constructing the graphs with the indicators on academic spin-offs. Furthermore, JQuery was used, which is a JavaScript library that simplifies the implementation of dynamic web pages;

iv. Bootstrap: responsive framework that allows the development of an easy-to-read web page and navigation regardless of the equipment and the client's monitor resolution. It was also used the "bootstrap-table" which is an extension of the functionalities of the tables created through the bootstrap; 
v. PHP: programming language for creating dynamic Web sites. The difference between PHP and JavaScript is that in PHP the source code runs on the server and only the html code is sent to the client. In this way, it becomes possible to interact with the database by not exposing the source code to the client;

vi. Maria DB: a database management system that is used for storing information regarding spin-offs, founders, universities, etc.

Specific languages and libraries were also used for the creation of frontend and backend modules. In the frontend, Canvas JS was also used as a tool for creating graphs using JavaScript and JVectorMap for rendering maps using the technologies interpreted by the latest browsers. On the other hand, in the backend was used the X-editable which is a tool to change editable elements and that interacts with the bootstrap-table and PHPExcel, which is a PHP library with a wide variety of methods for the manipulation of spreadsheet documents. This last library was essential in this project for the data migration between MS Excel and the application.

\section{Modeling}

An essential aspect in the implementation of this project is the modeling of the data transfer process between MS Excel and the application. This feature allows the data previously collected on each spin-off to be loaded in a quick and simplified way in the database without user intervention. It is in the data import process that PHPExcel library is used. Although it contains the most varied functions for spreadsheet manipulation, in the case of this project it is only intended to load the file to be imported, to access the various available sheets and to determine the value of the cells.

In the process of reading each cell, a set of processing operations is performed, such as removing white space and unnecessary characters, and checking if the content matches the expected data type. Additionally, the process checks the eventual existence of inject able SQL code. If the data don't accomplish all these requirements, the contents of the cell will be replaced by the null value.

Due to the high complexity of this process, the reading of the contents of each sheet will be separated by several modules, each of which will deal exclusively with the corresponding sheet. This situation is presented in Fig. 2. Before carrying out the import itself, it is necessary to clean the contents of the database. It is assumed, therefore, that the most updated information is always on the side of the Excel spreadsheet, and any changes of data on a spinoff must be performed using the backend module.

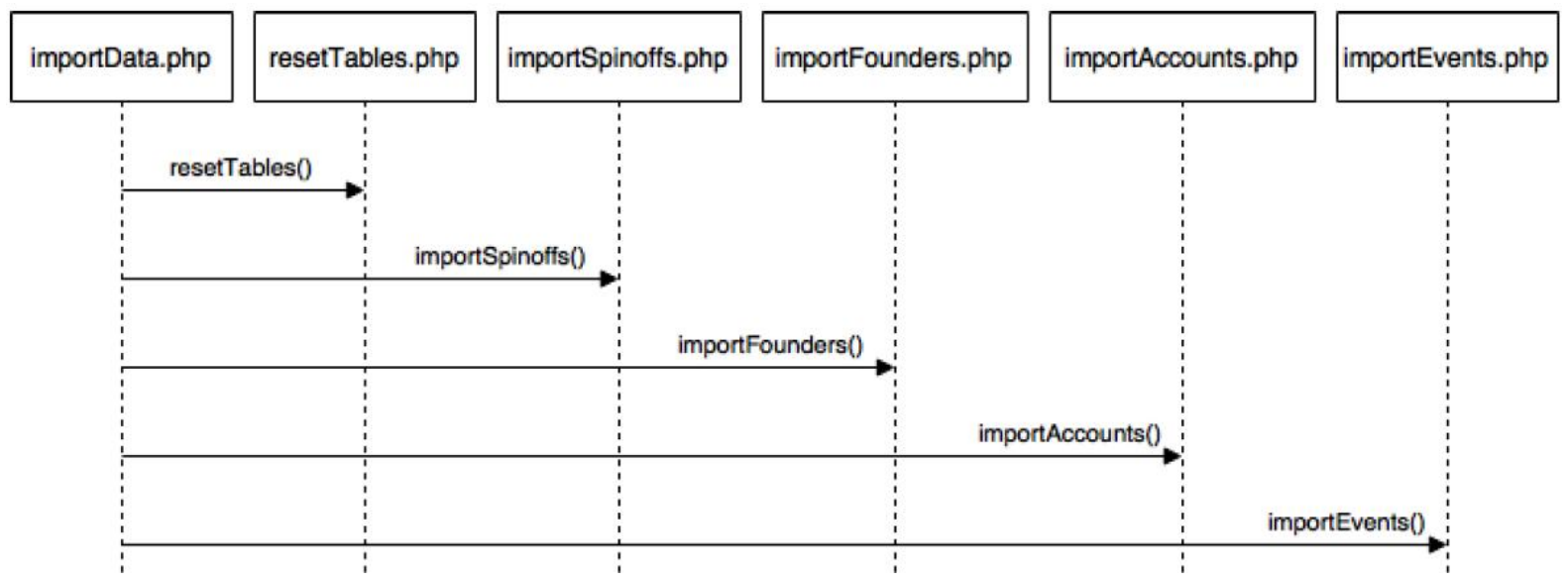

Fig. 2 Sequence diagram of the data import process

The "resetTables ()" module is responsible for deleting the various records stored in the different tables, since it has been defined to clean the database every time a new data import is performed. The "importSpinoffs( $)$ " module is responsible for storing data related to each academic spin-off. This information involves elements of multiple tables, so the data entry must follow a rigid order, in order to be able to relate the various records in the different tables. About each academic spin-off is known its activity sector, branches and institutions. This information is distributed in several columns, and in a given cell there may be elements separated by semicolons. During its reading and processing it is necessary to separate each of these entries so that it is verified whether or not it already exists in the database. This situation is illustrated in Fig. 3. 


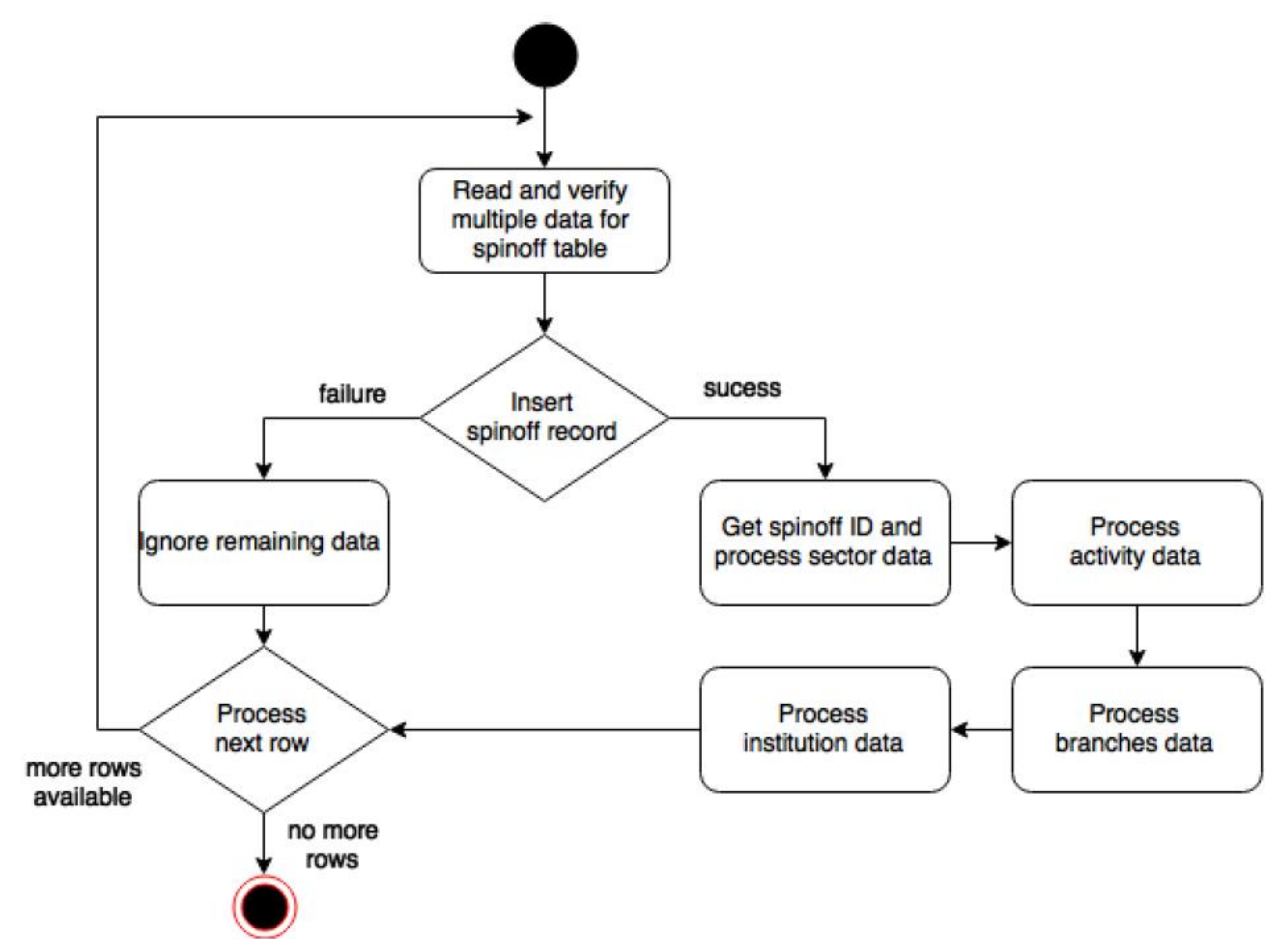

Fig. 3 Activity diagram of a new spin-off record insertion

The "inserFounders ()" module works on the same principles as "insertSpinoff ()", but with a set of data referring to the information about the people who created the spin-offs:

1. Data that is directly related to the fields in the "Founder" table (name and nationality);

2. Data associated with distinct table that have a many-to-many relationship with the "Founder" table (institution and top skills);

3. Data associated with distinct tables that have an one-to-many relationship with the "Founder" table (professional experience).

The "insertAccounts" and "insertEvents" modules don't have a so complex modeling process as the previous ones. Each of them only contains information directly related to the "Account" and "Event" tables. It is only necessary to check if the corresponding spin-off is already inserted in the DB. If it exists, simply gets the spin-off identifier and inserts a new record in the repeating table; otherwise, the information is discarded.

\section{Results}

ISO 9126 is the ISO standard responsible for the quality of software artifacts. It defines a set of parameters with the objective of standardizing the evaluation of software quality, assuming a fundamental role in the evaluation of the quality of Web applications. According to ISO 9126, six quality characteristics should be offered by software applications [20] : (i) functionality, implementation of the functional requirements specified by the customer; (ii) reliability, capability of software to maintain its performance level under given conditions of time; (iii) usability, the ease with people employ a tool or use an application to perform a task; (iv) efficiency, the relationship between the level of performance of the software and the amount of resource used under stated conditions; (v) maintainability, the effort needed to make specified modifications; and (v) portability, the ability of the software to be transformed from one environment to another. In the context of this project the sub-categories of these six groups proposed by ISO 9126 were not being exhaustively addressed and tested.

Several authors also discuss the properties that a Web-based application should offer. Reference [21] states the importance of developing web applications that provide high levels of reliability, usability, interoperability and security. Usability is also referred to by other authors as being an essential attribute of a Web application, in which it is suggested that refactoring the Web application's design structure can improve its usability [22]. Finally, it is important to recognize the relevant role of interoperability and portability, especially with the large-scale use of mobile devices [23]. 
In this sense, and in order to evaluate the quality of the developed application, several software tests were performed. For this purpose, the following criteria were considered: (i) functionality; (ii) usability; (iii) efficiency; and (iv) portability. On the other hand, the "reliability" and "maintainability" dimensions were not tested as it would require the application to be installed and intensively used during a considerable amount of time in the client's machine.

\section{A. Functionality}

Acceptance tests were performed on the specified requirements by the project manager. Each test case identifies success and failure cases, and the expected results. In total 48 acceptance tests were performed, 16 of them for the backend and 32 on the frontend. These tests involved multiple situations, such as incorrectly entering access credentials, importing data with an incorrect structure, editing spin-off data, querying detailed spin-off data, viewing the number of spin-offs created per year, among others.

Interoperability was also considered a very important functional requirement. Interoperability is defined as the ability of different types of applications to work together effectively, without prior communication, in order to exchange information in a useful and meaningful manner [24]. In this application there are two fundamental points of interoperability: (i) process of exporting data to an external application for statistical analysis (e.g. Stata, IBM SPSS, R Software, etc.); and (ii) use of the application database by external researchers.

The data export process allows data previously stored in the Maria DB to be read and analyzed by an external application. In this way, the range of options available to researchers that can incorporate data mining techniques directly into the web application or, alternatively, use statistical analysis and data mining tools known in the market as IBM SPSS, Stata or R. Therefore linear correlation, multiple analysis, scenario analysis, clustering, simulation models, among others can be applied to the data. It was tested the export of data to the Stata application, having for that purpose been used the Open Database Connectivity (ODBC) model. Maria DB has a connector designated by Maria DB Connector /ODBC that implements access to a Maria DB BD using the ODBC open connectivity standard.

Data stored in a Maria DB database can be downloaded and used for deep analytical and longitudinal studies for post-doctoral, doctoral and master students' researchers. Data is organized in four dimensions:

1. Institutional - include basic data from each spin-off, such as: creation date, extinction data (when applied), location, status, branches, legal form, sector of activity and host institution (university, polytechnic institute or R\&D center);

2. Founders - include basic data about name of the founders, academic degree, position inside the company and their nationality;

3. Accounts - provide detailed data about financial indicators for each spin-off;

4. Events - provide detailed data about different kind of corporate actions organized in three different areas: financials, strategy and recognition.

Additionally, security is another important component. The application offers protection against SQL injection. This type of failure occurs when a malicious user accesses the SQL code which allows him to access the data stored in the database [25]. This alternative access method can insert, change, or delete data and tables from the system database. In the application potential SQL injection issues can appear when reading the data field on the frontend and when loading data from an Excel file to the database. To mitigate the first situation regular expressions were used; while in the second scenario parameterized queries and stored procedures were adopted instead of chained user commands to determine SQL statements. Another concern is the encryption of the administrator's password for access to the backend. For this purpose a hash algorithm (SHA-3) was used that encodes the contents of the password stored in the database.

\section{B. Usability}

The usability of an interface is a fundamental point that shall be addressed when developing a Web application. Reference [26] proposes seven key design elements that should be adopted:

1. Navigation - we chose to use a navigation bar at the top of the page which offers consistency of navigation. The menu is composed of the following features: home, listing, results, dissemination, findings, downloads and contact. All these features are accessed through the menu with minimal backtracking/clicks;

2. Organization - spin-offs list can be customized by the user according to the company name, parent organization, faculty/R\&D center, date of incorporation, district and status (active or dissolved).

3. Graphical representation - through the use of bootstrap framework all images are dynamically adjusted to the user's browser and access device. A soft color scheme was also employed with an effective use of white space to avoid visual overload; 
4. Content utility - data on academic spin-offs are essentially useful for university institutions and research centers. It can also be a fundamental starting point for the establishment of public policies to support these entities;

5. Purpose - clear and unambiguous information about the purpose of the project is critical to understanding the project. In this sense, the "home" page contains information about the project promoters, the strategic objectives of the project and a clarification of the definition of the academic spin-off adopted in the scope of this project;

6. Simplicity - we sought to ensure an optimized design of the Web page through the adoption of a responsive design template. Additionally, the time required to find information on a given academic spin-off is reduced, since the user can directly search a company by its name;

7. Readability - all content is easy to read and intuitive. Each page of the application offers reduced content avoiding navigation through the scroll bar.

\section{Efficiency}

The performance of the application was tested considering two critical operations: the import phase of data on spin-offs and the process of consulting the data of the founders associated with each spin-off. Fig. 4 shows the amount of time needed to load data on academic spin-offs from an Excel file. Importing data on ten spin-offs take around $1.2 \mathrm{~ms}$ and increases to $98 \mathrm{~ms}$ for one hundred spin-offs. It was tested at most the existence of hundred thousand spin-offs that cause total loading time of 10,893 ms. It was verified that the import process had a linear growth according to the number of spin-offs. Fig. 5 shows the amount of time needed to show founder's info on the Web application. The existence of between two and ten founders by spin-offs was considered to test this scenario. The results indicate that the time required showing this information available to the user is relatively low, from 0.3 $\mathrm{ms}$ for two founders and $0.6 \mathrm{~ms}$ for ten founders.

\section{Importing spinoffs}

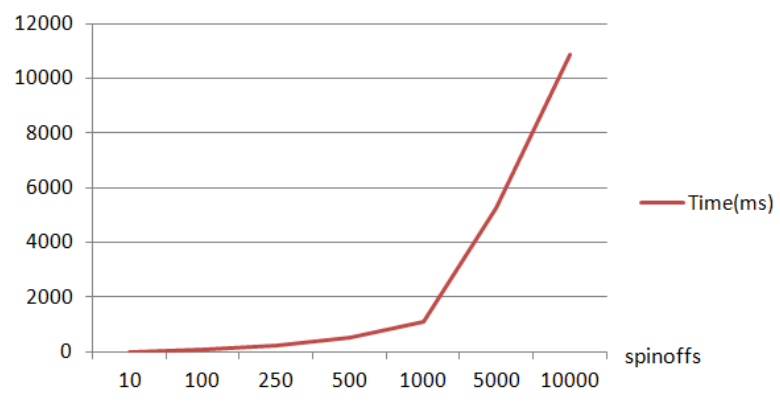

Fig. 4 Efficiency analysis of the importing spin-offs process

Show founders' info

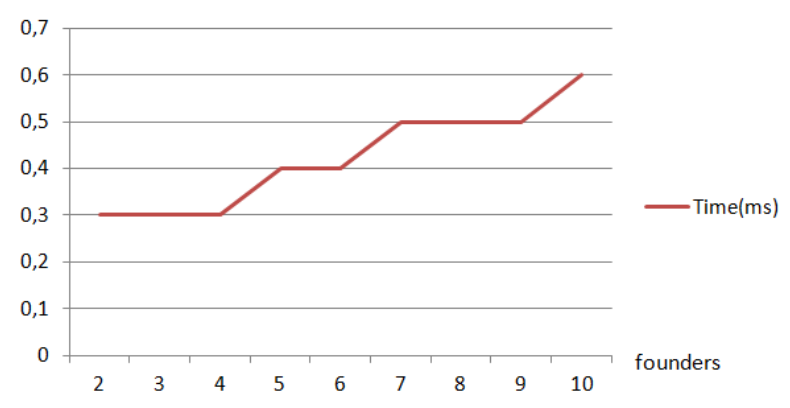

Fig. 5 Efficiency analysis of the founder's info process

\section{Portability}

Websites are increasingly being accessed through the use of tablets and smartphones. Therefore, it is imperative to offer an adequate user experience (UX) for these users. In this sense, the application has been tested in several portability test applications along the development process. For this purpose, three test platforms were considered: PageSpeed, mobiReady and Nibbler. These applications were chosen because they are freely available and they also 
give a set of improvement suggestions that have been progressively implemented in the application. These improvements included the use of image tags, validation of input fields and appropriate use of caching controls to speed page loading. The final results of the portability analysis can be consulted in Table 1 . The achieved results are generically positive in the three platforms, and still some suggestions for improvement can be implemented in a future version of the application.

TABLE 1

\begin{tabular}{lcl} 
& \multicolumn{2}{c}{ PORTABILITY ANALYSIS } \\
\hline \hline Platform & Score & Improvements \\
\hline PageSpeed & $88 / 100$ & - Eliminate render-blocking JavaScript and \\
& & CSS in above-the-fold content; \\
& - Leverage browser caching; \\
& - Optimize images. \\
& - Etag support; \\
mobiReady & - JavaScript placement; \\
& $0.71 / 1$ & - CSS measurements. \\
& & - Optimization of contents for tablets and \\
& & smartphones. \\
\hline
\end{tabular}

\section{Discussion}

The developed Web platform and its data model allow exploring the knowledge about academic spin-offs according to multiple perspectives. Conceptual frameworks proposed by several authors were considered in the process of defining the data model [13] [14] [15]. Only two of the mentioned dimensions by these authors were not incorporated: (i) the role of the university; and (ii) support organizations. Although scientific studies mention the importance of these two dimensions, these elements were not incorporated in this phase since it goes beyond the initial scope of this study that intends to focus essentially on the technology transfer process, and on the perception of the several antecedents and consequences of the academic entrepreneurship.

The Web platform is quite distinct from the existing projects to the current date on the analysis of academic spinoffs. Most of these projects have as main focus the scientific outcomes of academic entrepreneurship according multiples dimensions, such as identifying characteristics of founders' team, exploring the connection and dependencies between universities and academic spin-offs, or exploring the motivational factors for the creation of academic spin-offs. Little emphasis has been given to the component of dissemination and accessto the research results through a Web platform. Therefore, the data produced in the context of these studies are only available to a relatively small and strict community of researchers in this field. In spite of this, and considering the features implemented in the TASTE project, it is possible to conclude that this project has some similarities when looking to the considered dimensions for exploring data. The "firm", "institutions" and "individual" dimensions are common between both projects. However, the application developed incorporates four additional dimensions that are not considered in the TASTE project, respectively: (i) localization, which is only a sub-dimension of the contextual level in TASTE project, (ii) science parks, (iii) financial data; and (iv) corporate actions.

In relation to the other projects (spin-outs UK and Forny) the similarities are much smaller. The UK spin-outs essentially offers public data about the academic spin-offs created by each university and research center. This functionality was also implemented in the application, but it allows the user to query more elements like founder's info, incorporated date of the spin-off, associated events, etc. Additionally, the application offers an interactive way of exploring the results of the project according various dimensions (e.g., spin-offs created by region, spin-offs launched per year, spin-offs organized per activity sector, operating revenue by year, etc.) using JavaScript technology that is not implemented in UK spin-outs. Finally, in relation to FORNY, the similarities are even smaller, since the FORNY project is purely scientific, but had the merit of having been the first project in Europe that intends to analyze the process of commercialization of research projects developed by the universities.

Finally, it is important to emphasize the results obtained from the tests performed on the application according to multiple perspectives, such as functionality, usability, efficiency, portability, interoperability, security. All these perspectives were considered and evaluated in the application development process. These elements will play a fundamental role in the use of this application in a large-scale scenario.

\section{CONCLUSIONS}

The proposed web platform for the analysis of academic spin-offs will enable national and international stakeholders to produce evidence-based guidelines and policy tools, and synergistically to increase incentives for scientific production within this topic, fostering national and international community to produce high quality outputs. Additionally, it helps researchers to systematically analyze long-term evidence about academic spin-offs, their barriers, determinants and marker performance. 
The data organization in the application follows a multi-dimensional approach. A total of seven dimensions were considered, such as firm, institutions, individual, localization, science parks, financial data and corporate actions. Considering the similar projects available on this field, the proposed application is the only one that contemplates a greater number of dimensions. Additionally, it allows the data to be explored in real-time and interactively. Several key elements were considered in the development of a Web-like application, such as usability, security, interoperability and portability.

There are still some limitations in the application, which will be corrected and improved in future versions. Importing data from Excel to the application is only performed in the initial phase of the process, because all previously data stored in the application are replaced by the existing information in the Excel file. Updating data through the backend is useful and efficient for loading a small amount of data. However, for batch data loading this process proves to be less versatile and time-consuming. Additionally, the inclusion of corporate actions associated with each academic spin-off is also carried out manually in the backend. A future version of this application is currently being developing and intends to develop an automated process that employs data mining techniques and big data exploration tools to automatically find corporate actions associated with each academic spin-off.

\section{REFERENCES}

[1] H Etzjowitz, "Technology transfer : the second academic revolution," Technology Access Report, vol. 6, pp. 7 - 9, 1993. https://doi.org/10.1017/CBO9781139046930.004.

[2] A Pratiwi, W Sutopo, R Zakaria, and A Rasli , "Formulating Strategy Through QSPM Based on SWOT Framework: A Case Study Spin-Off Company in Malaysia," Abasyn Journal of Social Sciences, no. AIC, pp. 212 - 222, 2016.

[3] R Fini, Rosa Grimaldi, Simone Santoni, and Maurizio Sobrero, "Complements or substitutes? The role of universities and local context in supporting the creation of academic spin-offs," Research Policy, vol. $40, \quad$ pp. $1113 \quad$ - $1127,2011$. https://doi.org/10.1016/j.respol.2011.05.013.

[4] J Woolley, "Origins and Outcomes: The Roles of Spin-Off Founders and Intellectual Property in High-Technology Venture Outcomes," Academy of Management Discoveries, vol. 3, no. 1, pp. 64 - 90, 2017.

[5] L Arafeh, "An entrepreneurial key competencies' model," Journal of Innovation and Entrepreneurship, vol. 5, pp. 1 - $26,2016$. https://doi.org/10.1186/s13731-016-0048-6.

[6] W Valdivia, "University Start-Ups: Critical for Improving Technology Transfer," Center of Technology Innovation at Brookings, 2013.

[7] P Pattnaik and S Pandey, "University Spinoffs: What, Why, and How?," Technology Innovation Management Review, vol. 4, no. 12, pp. 44 $50,2014$.

[8] Giovanna Mariani, Ada Carlesi, and Alfredo Antonino Scarfò, "Academic spinoffs as a value driver for intellectual capital: the case of the University of Pisa," Journal of Intellectual Capital, vol. 19, no. 1, pp. 202 - 226, 2018. https://doi.org/10.1108/JIC-03-2017-0050.

[9] Bart Clarysse, Mike Wright, Andy Lockett, Philippe Mustar, and Mirjam Knockaert, "Academic spin-offs, formal technology transfer and capital raising," Industrial and Corporate Change, vol. 16, no. 4, pp. 609-640, 2007. https://doi.org/10.1093/icc/dtm019.

[10] Riccardo Fini, Kun Fu, Marius Mathisen, Einar Rasmussen, and Mike Wright, "Institutional Determinants of University Spin-Off Quantity and Quality: A Longitudinal, Multi-Level, Cross-Country Study," Small Business Economics, vol. 48, no. 2, pp. 361 - 391 , 2017.

[11] Barbara Bigliardi, Francesco Galati, and Chiara Verbano, "Evaluating Performance of University Spin-Off Companies: Lessons from Italy," Journal of Technology Management \& Innovation, vol. 8, no. 2, pp. 178 - 188, 2013. http://dx.doi.org/10.4067/S0718-27242013000200015.

[12] Einar Rasmussen, Øystein Moen, and Magnus Gulbrandsen, "Initiatives to promote commercialization of university knowledge," Technovation, vol. 26, no. 4, pp. 518-533, 2006. https://doi.org/10.1016/j.technovation.2004.11.005.

[13] Jahangir Yadollahi Farsi, Narges Imanipour, and Aidin Salamzadeh, "Entrepreneurial university conceptualization: case of developing countries," Global Business and Management Research: An International Journal, vol. 4, no. 2, pp. 193 - $204,2012$.

[14] Markus Perkmann et al., "Academic engagement and commercialisation: A review of the literature on university-industry relations," Research policy, vol. 42, no. 2, pp. 423 - 442, 2013. https://doi.org/10.1016/j.respol.2012.09.007.

[15] F Almeida, "Insights and Perspectives from a Literature Review on University Spin-Off," Management Resarch and Practice, vol. 10, no. 2, pp. $27-40,2018$.

[16] I Sommerville, Software Engineering, 10th ed. London, 2015.

[17] F Almeida, J Oliveira, and J Cruz, "Open Standards and Open Source: Enabling Interoperability," Internatonal Journal of Software Engineering \& Applications (IJSEA), vol. 2, no. 1, pp. 1 - 11, 2011.

[18] R Macredie and K Mijinyawa, "A theory-grounded framework of Open Source Software adoption in SMEs," European Journal of Information Systems, vol. 20, no. 2, pp. 237 - 250, 2011. https://doi.org/10.1057/ejis.2010.60.

[19] M. Khan and F. UrRehman, "Free and Open Source Software: Evolution, Benefits and Characteristics," International Journal of Emerging Trends \& technology in Computer Science, vol. 1, no. 3, pp. 1 - 7, 2012.

[20] D Nabil, A Mosad, and H Hefny, "Web-Based Applications quality factors: A survey and a proposed conceptual model," Egyptian Informatics Journal, vol. 12, pp. 211 - 217, 2011. https://doi.org/10.1016/j.eij.2011.09.003.

[21] Nimish Kumar, Reena Dadhich, and Aditya Shastri, "Quality Models for Web-based Application: A Comparative Study," International Journal of Computer Applications, vol. 125, no. 2, pp. 25 - 32, 2015. https://doi.org/10.5120/ijca2015905840.

[22] Alejandra Garrido, Gustavo Rossi, and Damiano Distante, "Refactoring for Usability in Web Applications," IEEE Software, vol. 28, no. 3, pp. 60 - 67, 2010. https://doi.org/10.5120/ijca201590584010.1109/MS.2010.114. 
[23] A Holzinger et al., "Making apps useable on multiple different mobile platforms: on interoperability for business application development on smartphones," in Multidisciplinary Research and Practice for Information Systems. Lecture Notes in Computer Science. Berlin: Springer, 2012, vol. 7465, pp. 176-189. https://doi.org/10.1007/978-3-642-32498-7_14.

[24] H. Panetto, "Towards a Classification Framework for Interoperability of Enterprise Applications," International Journal of Computer Integrated Manufacturing, vol. 20, no. 8, pp. 727-740, 2007.

[25] X. Ping-Chen, "SQL injection attack and guard technical research," Procedia Engineering, vol. 15, pp. 4131-4135, 2011. https://doi.org/10.1016/j.proeng.2011.08.775.

[26] R. Garett, J. Chiu, L. Zhang, and S. Young, "A Literature Review: Website Design and User Engagement," Online Journal of Communication Media Technology, vol. 6, no. 3, pp. 1 - 14, 2017. 